\title{
Evaluating the Business Intelligence and proposition of a Comprehensive model (the case of Nir Pars Company)
}

\author{
Davood Ghiyasvand \\ Corresponding Author, M.S. Candidate of Master Business Administration (MBA) \\ Isfahan Science and Research branch, Islamic Azad University, Isfahan, Iran \\ Hadi Teimouri \\ Assistant Professor, Management Department, University of Isfahan, Isfahan, Iran \\ Accepted: August 08, 2013 Published: Sep 14, 2013 \\ Doi:10.5296/ijld.v3i4.4273 URL: http://dx.doi.org/10.5296/ijld.v3i4.4273
}

\begin{abstract}
In the process of increasing development of different technology and tools in businesses, it seems that one of the most important success factors in businesses is decision-making and selection of best information in shortest time with highest confidence. Business Intelligence is a new approach, which provides quick access to data and analysis on demand.

The purpose of this article is to explore the level of business intelligence and propose a comprehensive model for Nir Pars Company. This is an applied, descriptive-correlation research, conducted by survey methodology. A collection of 400 experts and managers of different organizational levels of Nir Company were selected as the statistical population of the study and a batch of 225 persons were chosen by simple random sampling. Library method was used for Data gathering to form the theoretical foundations of the research, and we used our own questionnaire to confirm or refute the research hypotheses; which has the required reliability and validity (Cronbach's alpha coefficient of 0.980). To explore the relationships between the elements of the Model, factor analysis and structural equation modeling techniques were used. According to achieved results, the business intelligence exceeds 0.69 (for all parameters of the model).
\end{abstract}

Keywords: Business intelligence, Intelligence Relationship, Intelligence Competencies, Analytical skills, Business Skills.

\section{Introduction}

Due to ever-increasing pace of globalization and extreme changes in the present age, organizations need to admit that the philosophy of their lives has changed and to live no longer might not mean to achieve sustainable profitability status. Communities and the market with an indescribable haste look for tactics to ensure its survival in the chaotic and turbulent era. In such circumstances, trends of the past or the current situation cannot be the basis for predicting future. Insisting on old-fashioned business methods and past strategies no longer is efficient enough to survive, so the utilization of new knowledge and tools is a necessity. In order to succeed in the future, managers must learn to play their role, respond to the environment quickly and accurately and make decisions in time. In this situation, managers and employees should be familiar with the concepts of Information Technology and its innovations, in addition to its role in business in the third millennium, to use them in moving toward organization goals and entrepreneurship. One of the concepts related to information technology is organization and business intelligence through which organizations can achieve 
the competitive advantage in business. Therefore, mastering new technologies such as business intelligence is considered an inevitable necessity and requirement.

Business intelligence systems provide a means by which the information needs are properly addressed. Because of the needs of customers and the state regulations vary, and power tools in market and issues like competition, imposes pressures on organization. Therefore, organizations must somehow be equipped. In the meantime, business intelligence tools can help organizations to analyze their surroundings and make decision based on necessary predictions. Business intelligence software can help them to turn all the raw data into an extensive knowledge, so that managers make reliable decisions. In fact, business intelligence allows people at any level of organization to access information, interact and analyze them in order to manage the business, improve efficiency, discover success factors and efficiently realize organizational operations. [8]

In fact, the architecture of business intelligence is a process in which core business functions and processes are equipped and rebuilt based on new tools and technologies such as telephone, Fax, Internet, network, Web, email, e-commerce and e-marketing, etc. Nowadays, one can claim with full confidence that the use of business intelligence solutions can enhance an organization's competitive strength and distinguishes it from other organizations. This solution makes it possible for organizations to exploit the benefits of leading and being competitive by means of existing data. This gives a better understanding of the demands and needs of our customers and relationship management with them. [12]

In this study, a survey on the level of business intelligence and proposition of a comprehensive model for various aspects of business intelligence is conducted in Nir Pars Company of Tehran. Literature reviews shows us that several attempts has been made in recent years to study business intelligence. None of the previous research in Iran has provided a model that includes all the variables affecting business intelligence. Thus, researchers seek to provide a conceptual model for "business intelligence" in Nir Pars Company.

\section{Theoretical Foundations}

\subsection{Models of Business Intelligence}

For designing conceptual model of research, some researches on Business Intelligence were investigated, including: Bahrami M, Arabzad M and Ghorbani M. Model (2012) [3]; Olszak CM and Ziemba E. Model (2007) [10] and Green a. Model (2007) [7]. Then by integrating some model variables of Business Intelligence in the above mentioned researches according to the facts of statistical population under study, the conceptual model of research was designed.

\subsection{Dimensions of "Business Intelligence" model}

- Business Intelligence: Solutions for collecting and integrating, analyzing and providing access to information in a way that allows the user to make better business decisions. [1] It makes real-time information reach to centralized repository and provide analysis that can be used at any horizontal or vertical level of commercial institution. [9]

- Intelligence Relationship: This intelligence represents the understanding about how employee interactions affect organizational performance and implies the relationships between people in an organization and the way they deal with each other. Among these relations are the relationships with employees and the organization's relationships with suppliers. [7] 
- Intelligence Competencies: This intelligence represents the understanding about how capabilities and expertise of the staff affects organizational performance and requires adequate and appropriate technologies and information. [7]

- Analytical skills: This type of skill requires analysis of information and organizational decisions, developing the various options of decision making, exploring and explaining the issues in order to improve decisions and tasks and to expedite achieving organizational goals and performance that is more effective.

- Business skills: Nowadays in information society people require a set of skills that help them to start a business, and with the properly direction, it will also facilitates the business progress. These skills include English proficiency, ability to work with computer and use Internet, supervision and leadership skills, marketing and familiarity with finance and economics. [2]

- Information Technology Skills: utilizes techniques, tools and applications such as online transaction processing, on-line analytical processing, analytical database, data mining and knowledge management to analyze and improve the quality of operations and increase organizational awareness. [6]

\section{Conceptual Model and Hypotheses}

Hypotheses that can be derived from the conceptual model of "Business Intelligence" are as follows:

H1: The level of Business Intelligence in terms of the "Business Skills" variable in Nir Pars Company is above average.

H2: The level of Business Intelligence in terms of the "Intelligence Relationship Skill" variable in Nir Pars Company is above average.

H3: The level of Business Intelligence in terms of the "Intelligence Competencies Skill" variable in Nir Pars Company is above average.

H4: The level of Business Intelligence in terms of the "Analytical skills" variable in Nir Pars Company is above average.

H5: The level of Business Intelligence in terms of the "Business Skills" variable in Nir Pars Company is above average.

H6: The level of Business Intelligence in terms of the "Information Technology skills" variable in Nir Pars Company is above average.

The conceptual model including research hypotheses are shown in Figure 1. 


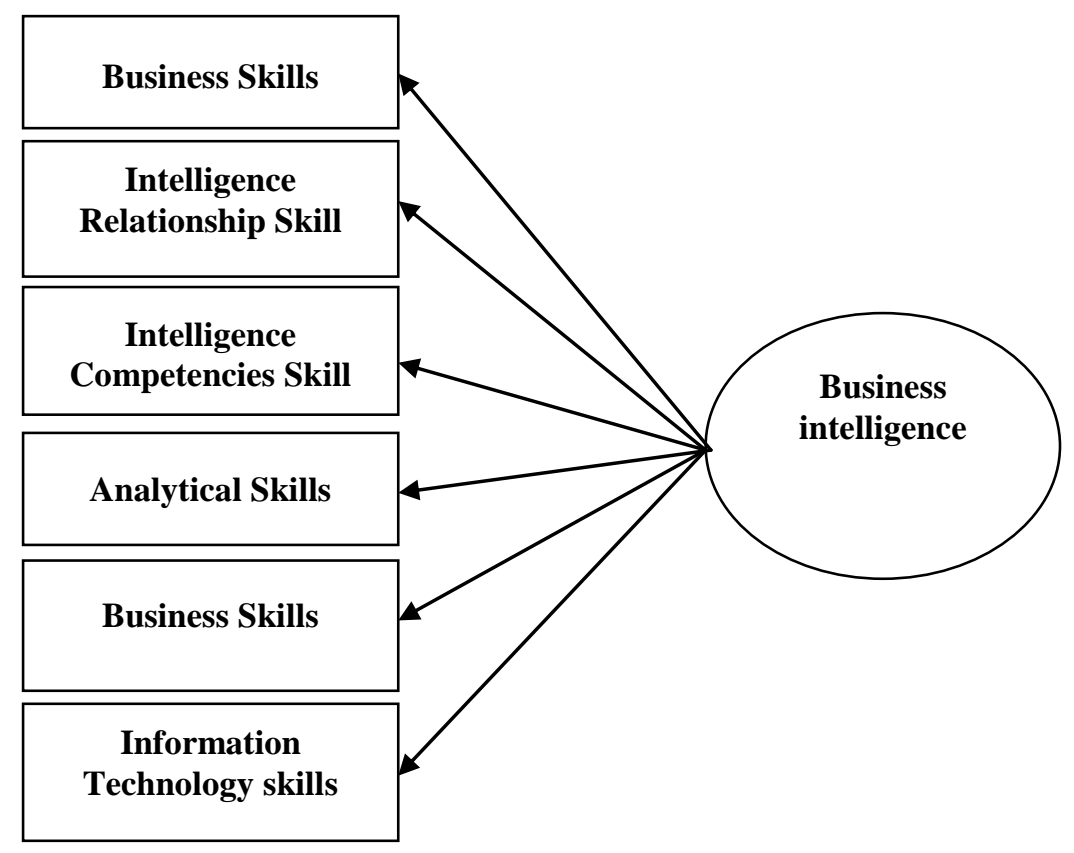

Figure 1: Research proposed model

\section{Research Methodology}

The research method of the paper is "applied" in terms of objective and "descriptivecorrelation" in nature. To collect information about the literature review, library method including reading books, journals, and internet searching was used and we designed our own questionnaire to confirm or refute the research hypotheses. The research method in this paper is field study. The statistical population of the study consists of all experts and managers of different organizational levels in Nir Pars Company. After the identification of indicators, 225 questionnaires were distributed to a random sample of experts and executives of Nir Pars Company, 211 completed questionnaires were returned. Finally, using Exploratory Factor Analysis (EFA) and Structural Equation Modeling (SEM), the proposed conceptual model of research was analyzed. To analyze the obtained data in the quantitative section, we use descriptive statistics methods such as mean, frequency and inferential statistics and structural equation testing method. The aforementioned data will be analyzed using SPSS and LISREL statistical software.

\subsection{Validity and reliability of questionnaire}

Cronbach's alpha was used to assess the reliability of measuring instruments. The result of Cronbach's alpha of the 30 pre-test questionnaires was 0.980 . To examine the validity of the questionnaire, "content validity" and "structural validity" were used.

Content validity: Experts' judgment about how the questions of a test represent content and purpose of a program or content scope is used to determine the content validity of a test. For this purpose and to evaluate the research questionnaire, after establishing the basic framework, viewpoints of 16 persons (including 14 managers and experts in NIR Pars and 2 university teachers) were presented, put to the vote and approved. 
Structural validity: Structural validity of a measuring instrument represents how it measures an attribute or structure which has the theoretical basis. Exploratory factor analysis and particularly factorial validity index were used to assess structural validity of questionnaire. In factor analysis the questions that were designed to evaluate an attribute or indicator should have common load factor and these factors need to be meaningful. So, all of the research questions that were designed using valid scientific questionnaires underwent exploratory factor analysis. Since the confirmatory factor analysis is analyzed in terms of a measurement model, and the fitness and validity of the model are discussed in its results, so the results of fitting measurement model are presented in what follows.

\subsection{Statistical population and sample of research}

The statistical population of this research consists of 400 experts and managers at various levels of Nir Pars Company. Simple random sampling method was used. In this method sample size is obtained using Cochran's formula [4].

$$
\mathrm{n}=\frac{N \times \mathrm{Z}^{2} \alpha / 2 \times \sigma^{2}}{\mathrm{Z}^{2} \alpha / 2 \times \sigma^{2}+(\mathrm{N}-1) \times \varepsilon^{2}}
$$

In this formula, $\delta$ is the primary sample standard deviation for the entire questionnaire, $\varepsilon$ is the amount of allowable error, $\mathrm{Z}=0.05$ is the unit normal variable corresponding to confidence level of $95 \% ;\left(\mathrm{Z}_{\alpha / 2}=1.96\right)$ and statistical population $\mathrm{N}$ is 400 .

$$
\mathrm{n}=\frac{N \times \mathrm{Z}^{2} \alpha / 2 \times \sigma^{2}}{\mathrm{Z}^{2} \alpha / 2 \times \sigma^{2}+(\mathrm{N}-1) \times \varepsilon^{2}} \Rightarrow \mathrm{n}=\frac{400 \times(1.96)^{2} \times(0.57058)^{2}}{(1.96)^{2} \times(0.57058)^{2}+(400-1) \times(0.05)^{2}} \Rightarrow \mathrm{n}=224.62 \sim 225
$$

Given that the statistical population of this research is 400, according to Morgan table (1969) the desired sample size is 196. And Given that estimated standard deviation of the pilot sample $(n=30)$ equals 0.57058 ; and the other hand, due to the size of staff population based on Cochran's formula, sample size is at least 225 questionnaire. In this regard, 225 randomly selected questionnaires were distributed in the statistical population. Finally, after three stages of follow-ups (face to face, phone and email) 217 questionnaires were returned, which only 211 of them were completed.

\section{Data Analysis}

Inferential statistical techniques, especially exploratory factor analysis and confirmatory factor analysis were used for data analysis. First a set of 32 items related to "Business Intelligence" are factored using factor analysis. These outputs can be used for confirmatory factor analysis. In fact during the exploratory factor analysis, items are classified by the appropriate style. Then this factorization during the confirmatory factor analysis can be approved or rejected in structural equation modeling technique. The exploratory factor analysis was done by SPSS 19 and the confirmatory factor analysis by LISREL 8.8 . The outputs of exploratory factor analysis and structural equation modeling will be presented. 


\subsection{Data Analysis using factor analysis}

Factor analysis tries to identify the underlying variables or factors to explain the pattern of correlations between observed variables. Factor analysis can be divided into two types of Exploratory and confirmatory categories. To perform a factor analysis the following four major steps are essential: 1- Forming a matrix of correlation coefficients from all the variables used in the analysis and estimation of subscription, 2- Extracting factors from correlation matrix, 3-Factor selection and rotation, 4- Analyzing the results [11].

After a factor analysis of 32 item questionnaire, based on data collected from 211 questionnaires, the KMO test index is 0.932 , which is greater than 0.6 and indicates the adequacy of sample size. Also given that the sig value of Bartlett test is smaller than $5 \%$.

As shown in Table 1 in this case factors 1 through 6 have Eigen values greater than 1 and remained in the analysis. In fact, the table suggests that the questionnaire, together with 6 factors and total explained variance higher than 79.099\%, could assess the "Business Intelligence". This shows the appropriate construct validity of the questions.

Table 1: Total Variance Explained "Business Intelligence"

\begin{tabular}{|c|c|c|c|c|c|c|c|c|c|}
\hline \multirow{2}{*}{$\begin{array}{c}\text { Dimensions of } \\
\text { Business } \\
\text { Intelligence }\end{array}$} & \multicolumn{3}{|c|}{ Initial Eigen values } & \multicolumn{3}{|c|}{$\begin{array}{c}\text { Extraction Sums of } \\
\text { Squared Loadings }\end{array}$} & \multicolumn{3}{c|}{$\begin{array}{c}\text { Rotation Sums of } \\
\text { Squared Loadings }\end{array}$} \\
\cline { 2 - 10 } & Total & $\begin{array}{c}\text { \% of } \\
\text { Varianc } \\
\text { e }\end{array}$ & $\begin{array}{c}\text { Cumulati } \\
\text { ve \% }\end{array}$ & $\begin{array}{c}\text { Total of } \\
\text { Varianc } \\
\text { e }\end{array}$ & $\begin{array}{c}\text { Cumulati } \\
\text { ve \% }\end{array}$ & $\begin{array}{c}\text { \%of } \\
\text { Varianc } \\
\text { e }\end{array}$ & $\begin{array}{c}\text { Cumulati } \\
\text { ve \% }\end{array}$ \\
\hline $\begin{array}{c}\text { Intelligence } \\
\text { Competencies } \\
\text { Skill (ICS) }\end{array}$ & $\mathbf{1 7 . 0 1 8}$ & 53.181 & 53.181 & 17.018 & 53.181 & 53.181 & 5.838 & $\mathbf{1 8 . 2 4 4}$ & 18.244 \\
\hline $\begin{array}{c}\text { Organizational } \\
\text { skills (OS) }\end{array}$ & $\mathbf{2 . 7 7 9}$ & 8.684 & 61.865 & 2.779 & 8.684 & 61.865 & 4.628 & $\mathbf{1 4 . 4 6 1}$ & 32.705 \\
\hline $\begin{array}{c}\text { Intelligence } \\
\text { Relationship } \\
\text { Skill (IRS) }\end{array}$ & $\mathbf{1 . 9 0 6}$ & 5.957 & 67.822 & 1.906 & 5.957 & 67.822 & 4.214 & $\mathbf{1 3 . 1 7 0}$ & 45.875 \\
\hline $\begin{array}{c}\text { Business Skills } \\
\text { (BS) }\end{array}$ & $\mathbf{1 . 3 5 9}$ & 4.246 & 72.068 & 1.359 & 4.246 & 72.068 & 4.069 & $\mathbf{1 2 . 7 1 5}$ & 85.590 \\
\hline $\begin{array}{c}\text { Analytical Skills } \\
\text { (AS) }\end{array}$ & $\mathbf{1 . 2 4 7}$ & 3.898 & 75.966 & 1.247 & 3.898 & 75.966 & 3.596 & $\mathbf{1 1 . 2 3 9}$ & 69.829 \\
\hline $\begin{array}{c}\text { Information } \\
\text { Technology } \\
\text { skills (ITS) }\end{array}$ & $\mathbf{1 . 0 0 3}$ & 3.133 & 79.099 & 1.003 & 3.133 & 79.099 & 2.966 & $\mathbf{9 . 2 7 0}$ & $\mathbf{7 9 . 0 9 9}$ \\
\hline
\end{tabular}

According to Table (1), the first factor, i.e. "Intelligence Competencies Skill" explains 17.01\%; the second factor, "Organizational skills" about 2.77\%; the third factor, "Intelligence Relationship Skill" about 1.90\%; the fourth factor "Business Skills" about 1.35\%; the fifth factor "Analytical Skills" about $1.24 \%$ and the sixth factor, "Information Technology skills" about $1.00 \%$ variance of "Business Intelligence", which actually indicates the importance of factors in formation of the "Business Intelligence" structure. The rotated factor matrix of these fields will be presented which indicates what questions and at what factor load are related to these factors. Table (2) represents factorial rotation matrix.

It is not easy to interpret factor loadings without rotation. Therefore, factors rotation tries to increase the Interpretability. Table 2 shows the rotated factor matrix. 
Table 2: Rotated component matrix "Business Intelligence"

\begin{tabular}{|c|c|c|c|c|c|c|}
\hline \multirow[b]{2}{*}{ variables } & \multicolumn{6}{|c|}{ component } \\
\hline & $\begin{array}{l}\text { Intelligence } \\
\text { Competencie } \\
\text { s Skill (ICS) }\end{array}$ & $\begin{array}{l}\text { Organizatio } \\
\text { nal skills } \\
(\mathrm{OS})\end{array}$ & $\begin{array}{l}\text { Intelligence } \\
\text { Relationship } \\
\text { Skill (IRS) }\end{array}$ & $\begin{array}{c}\text { Business } \\
\text { Skills (BS) }\end{array}$ & $\begin{array}{l}\text { Analytical } \\
\text { Skills (AS) }\end{array}$ & $\begin{array}{l}\text { Information } \\
\text { Technology } \\
\text { skills (ITS) }\end{array}$ \\
\hline IRS1 & .131 & .229 & .785 & .225 & .172 & .203 \\
\hline IRS2 & .155 & .268 & .764 & .274 & .166 & .200 \\
\hline IRS3 & .184 & .287 & .743 & .229 & .267 & .190 \\
\hline IRS4 & .226 & .291 & .729 & .202 & .218 & .170 \\
\hline IRS5 & .216 & .269 & .778 & .186 & .186 & .185 \\
\hline ICS1 & .775 & .180 & .023 & .210 & .127 & .171 \\
\hline ICS2 & .827 & .145 & .115 & .163 & .154 & .188 \\
\hline ICS3 & .793 & .183 & .178 & .222 & .097 & .089 \\
\hline ICS4 & .804 & .230 & .242 & .173 & .164 & .089 \\
\hline ICS5 & .834 & .156 & .130 & .146 & .149 & .103 \\
\hline ICS6 & .802 & .167 & .187 & .179 & .161 & .141 \\
\hline ICS7 & .832 & .159 & .104 & .136 & .148 & .114 \\
\hline OS1 & .251 & .724 & .266 & .240 & .140 & .213 \\
\hline OS2 & .262 & .692 & .252 & .289 & .201 & .196 \\
\hline OS3 & .207 & .734 & .197 & .186 & .175 & .238 \\
\hline OS4 & .249 & .743 & .235 & .209 & .161 & .199 \\
\hline OS5 & .228 & .732 & .280 & .232 & .126 & .218 \\
\hline OS6 & .181 & .701 & .286 & .192 & .181 & .258 \\
\hline ITS1 & .239 & .305 & .244 & .226 & .187 & .712 \\
\hline ITS2 & .234 & .373 & .276 & .217 & .147 & .671 \\
\hline ITS3 & .215 & .277 & .241 & .229 & .213 & .742 \\
\hline ITS4 & .197 & .318 & .224 & .267 & .126 & .741 \\
\hline BS1 & .260 & .278 & .316 & .637 & .275 & .211 \\
\hline BS2 & .309 & .159 & .246 & .716 & .236 & .155 \\
\hline BS3 & .254 & .269 & .309 & .704 & .173 & .167 \\
\hline BS4 & .270 & .218 & .154 & .717 & .297 & .149 \\
\hline BS5 & .179 & .341 & .183 & .659 & .290 & .214 \\
\hline BS6 & .261 & .246 & .225 & .716 & .100 & .275 \\
\hline AS1 & .188 & .179 & .149 & .223 & .834 & .116 \\
\hline AS2 & .200 & .161 & .155 & .283 & .782 & .136 \\
\hline AS3 & .212 & .201 & .247 & .145 & .811 & .108 \\
\hline AS4 & .189 & .133 & .236 & .189 & .805 & .169 \\
\hline
\end{tabular}

Extraction Method: Principal Component Analysis. 


\begin{tabular}{|c|c|c|c|c|c|c|}
\hline \multirow[b]{2}{*}{ variables } & \multicolumn{6}{|c|}{ component } \\
\hline & $\begin{array}{c}\text { Intelligence } \\
\text { Competencie } \\
\text { s Skill (ICS) }\end{array}$ & $\begin{array}{l}\text { Organizatio } \\
\text { nal skills } \\
\text { (OS) }\end{array}$ & $\begin{array}{l}\text { Intelligence } \\
\text { Relationship } \\
\text { Skill (IRS) }\end{array}$ & $\begin{array}{c}\text { Business } \\
\text { Skills (BS) }\end{array}$ & $\begin{array}{c}\text { Analytical } \\
\text { Skills (AS) }\end{array}$ & $\begin{array}{l}\text { Information } \\
\text { Technology } \\
\text { skills (ITS) }\end{array}$ \\
\hline IRS 1 & .131 & .229 & .785 & .225 & .172 & .203 \\
\hline IRS2 & .155 & .268 & .764 & .274 & .166 & .200 \\
\hline IRS3 & .184 & .287 & .743 & .229 & .267 & .190 \\
\hline IRS4 & .226 & .291 & .729 & .202 & .218 & .170 \\
\hline IRS5 & .216 & .269 & .778 & .186 & .186 & .185 \\
\hline ICS1 & .775 & .180 & .023 & .210 & .127 & .171 \\
\hline ICS2 & .827 & .145 & .115 & .163 & .154 & .188 \\
\hline ICS3 & .793 & .183 & .178 & .222 & .097 & .089 \\
\hline ICS4 & .804 & .230 & .242 & .173 & .164 & .089 \\
\hline ICS5 & .834 & .156 & .130 & .146 & .149 & .103 \\
\hline ICS6 & .802 & .167 & .187 & .179 & .161 & .141 \\
\hline ICS7 & .832 & .159 & .104 & .136 & .148 & .114 \\
\hline OS1 & .251 & .724 & .266 & .240 & .140 & .213 \\
\hline OS2 & .262 & .692 & .252 & .289 & .201 & .196 \\
\hline OS3 & .207 & .734 & .197 & .186 & .175 & .238 \\
\hline OS4 & .249 & .743 & .235 & .209 & .161 & .199 \\
\hline OS5 & .228 & .732 & .280 & .232 & .126 & .218 \\
\hline OS6 & .181 & .701 & .286 & .192 & .181 & .258 \\
\hline ITS1 & .239 & .305 & .244 & .226 & .187 & .712 \\
\hline ITS2 & .234 & .373 & .276 & .217 & .147 & .671 \\
\hline ITS3 & .215 & .277 & .241 & .229 & .213 & .742 \\
\hline ITS4 & .197 & .318 & .224 & .267 & .126 & .741 \\
\hline BS1 & .260 & .278 & .316 & .637 & .275 & .211 \\
\hline BS2 & .309 & .159 & .246 & .716 & .236 & .155 \\
\hline BS3 & .254 & .269 & .309 & .704 & .173 & .167 \\
\hline BS4 & .270 & .218 & .154 & .717 & .297 & .149 \\
\hline BS5 & .179 & .341 & .183 & .659 & .290 & .214 \\
\hline BS6 & .261 & .246 & .225 & .716 & .100 & .275 \\
\hline AS1 & .188 & .179 & .149 & .223 & .834 & .116 \\
\hline AS2 & .200 & .161 & .155 & .283 & .782 & .136 \\
\hline AS3 & .212 & .201 & .247 & .145 & .811 & .108 \\
\hline AS4 & .189 & .133 & .236 & .189 & .805 & .169 \\
\hline
\end{tabular}

Rotation Method: Varimax with Kaiser Normalization.

a. Rotation converged in 6 iterations. 
According to Table 2, we can come to the conclusion that the factors affecting "Business Intelligence" are classified in 6 groups which examine "Business Intelligence" considering "total converted variance" of $79.099 \%$.

\subsection{Data Analysis by Structural Equation Modeling}

To examine the causal relationships between variables in a coherent form, lots of efforts have been made in the past decade. One of the promising methods in this field is structural equation modeling or multivariate analysis with latent variables. This method is also known as the causal model and Covariance structure analysis by Bentler in 1980.Through this method; one can test the acceptability of theoretical models in particular populations using correlation, non-experimental and experimental data.

Structural equation modeling is a very wide and powerful multivariate analysis technique from the multiple regressions category that allows the researcher to examine a series of regression equations simultaneously. This method is a comprehensive statistical approach for testing hypotheses about the relationships between observed and latent variables [4]. When the data obtained from the sample changes to covariance or correlation matrix and is defined by a set of regression equations, then the model can be analyzed using the relevant software's and test its fit for the population from which sample was extracted. This analysis provides estimations of the model parameters (path coefficients and error terms) and some indicators for goodness of fit. Parameter estimates and information about goodness of fit can be used for testing possible changes in the model and re-examining the theoretical model [11].

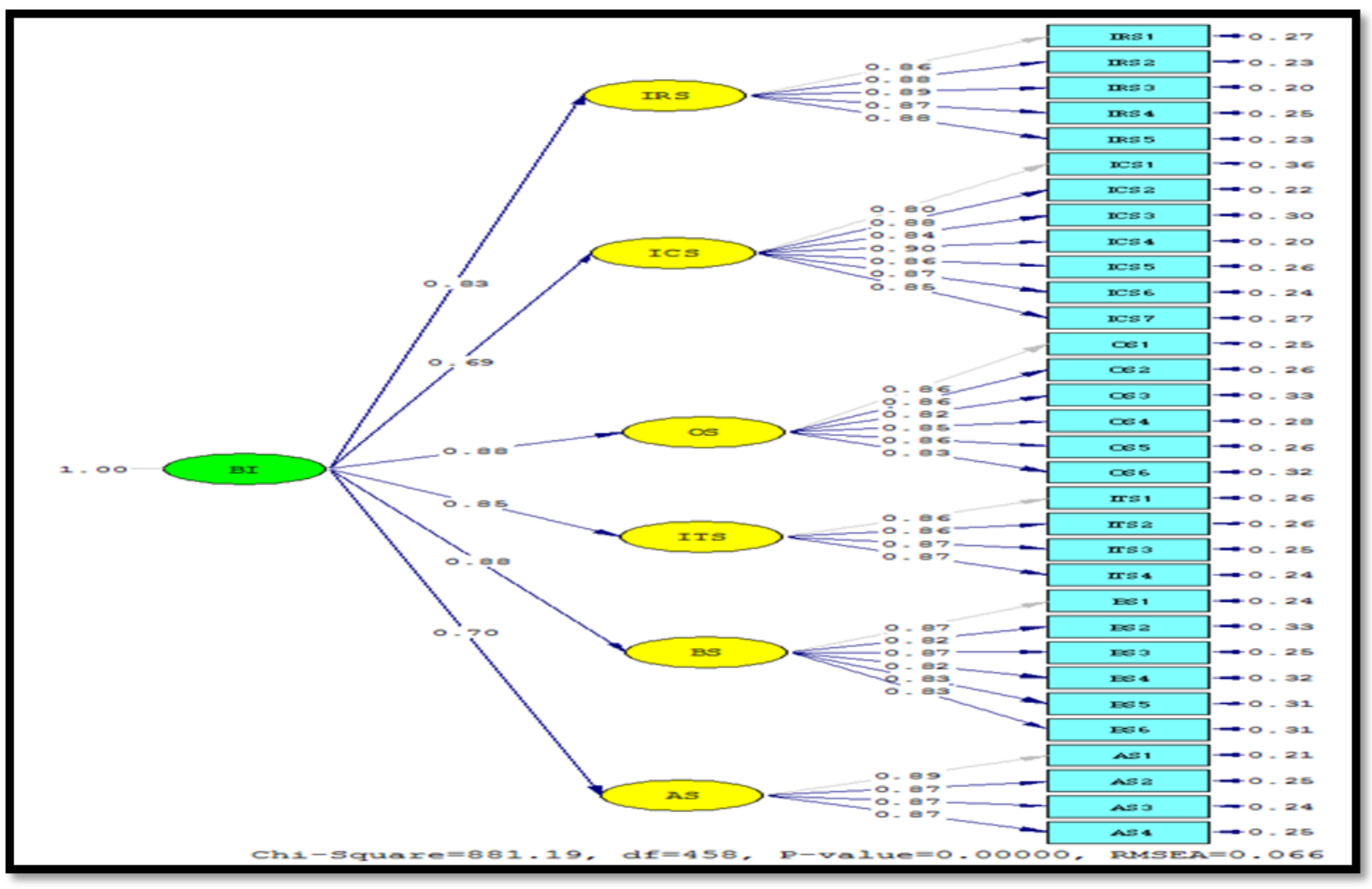

Figure 2: Standardized Solutions Model for "Business Intelligence" 


\section{Macrothink}

Figure (2) indicates that to what extents each of these factors explain the "Business Intelligence (BI)" in the final model. The priority of these factors is as follows:

1. Organizational skills (OS) and Business Skills (BS) both with 0.88 path factor,

2. Information Technology skills (ITS) with 0.85 path factor,

3. Intelligence Relationship Skill (IRS) with 0.83 path factor,

4. Analytical Skills (AS) with 0.70 path factor,

5. Intelligence Competencies Skill (ICS) with 0.69 path factor.

Also, based on figure (2), the following results for each aspect were obtained:

The most important indicator in "Intelligence Relationship Skill (IRS)" is "continuous communication with customers and receiving feedback in order to determine their needs and expectations" (with IRS3 code), with correlation coefficient of $89 \%$.

* The most important indicator in "Intelligence Competency Skill" is "ability to analyze the performance of successful and unsuccessful competitors and organizations" " (with ICS4 code), with correlation coefficient of $90 \%$.

* The most important indicators in "Organizational Skills" are "ability to make changes in the organizational structure suited for the changing environment", "propagating openness, change acceptance and new and major ways of thinking about business" and "ability to design organizational processes needed to accomplish organizational policies and strategies" (with OS2, OS1 and OS5 codes respectively) which all have a correlation coefficient of $86 \%$.

* The most important indicators in "Information Technology Skill (ITS)" are "ability to create a technical and architectural platform for expansion and optimal use of resources" and "the ability to use updated information and communication technologies to enhance and improve the effectiveness of organizations' processes" (with ITS3 and ITS4 codes respectively) which both have a correlation coefficient of $87 \%$.

* The most important indicators in "Business Skills" are "ability to collect and analyze the information in order to identify, understand and anticipate the needs and expectations of corporate stakeholders" and "ability to create alignment at different levels of organizational strategies" (with BS1 and BS3 codes respectively) which both have a correlation coefficient of $87 \%$.

* Finally, the most important indicator in "Analytical Skills (AS)" is "ability to develop innovative technology (attempting to replace outdated technology) and management of organizational technology portfolios" with code AS1 (and a correlation coefficient of $89 \%)$.

Figure (3) shows the model of meaningful number of "Business Intelligence (BI)". 
Figure 3: T-Values for "Business Intelligence"

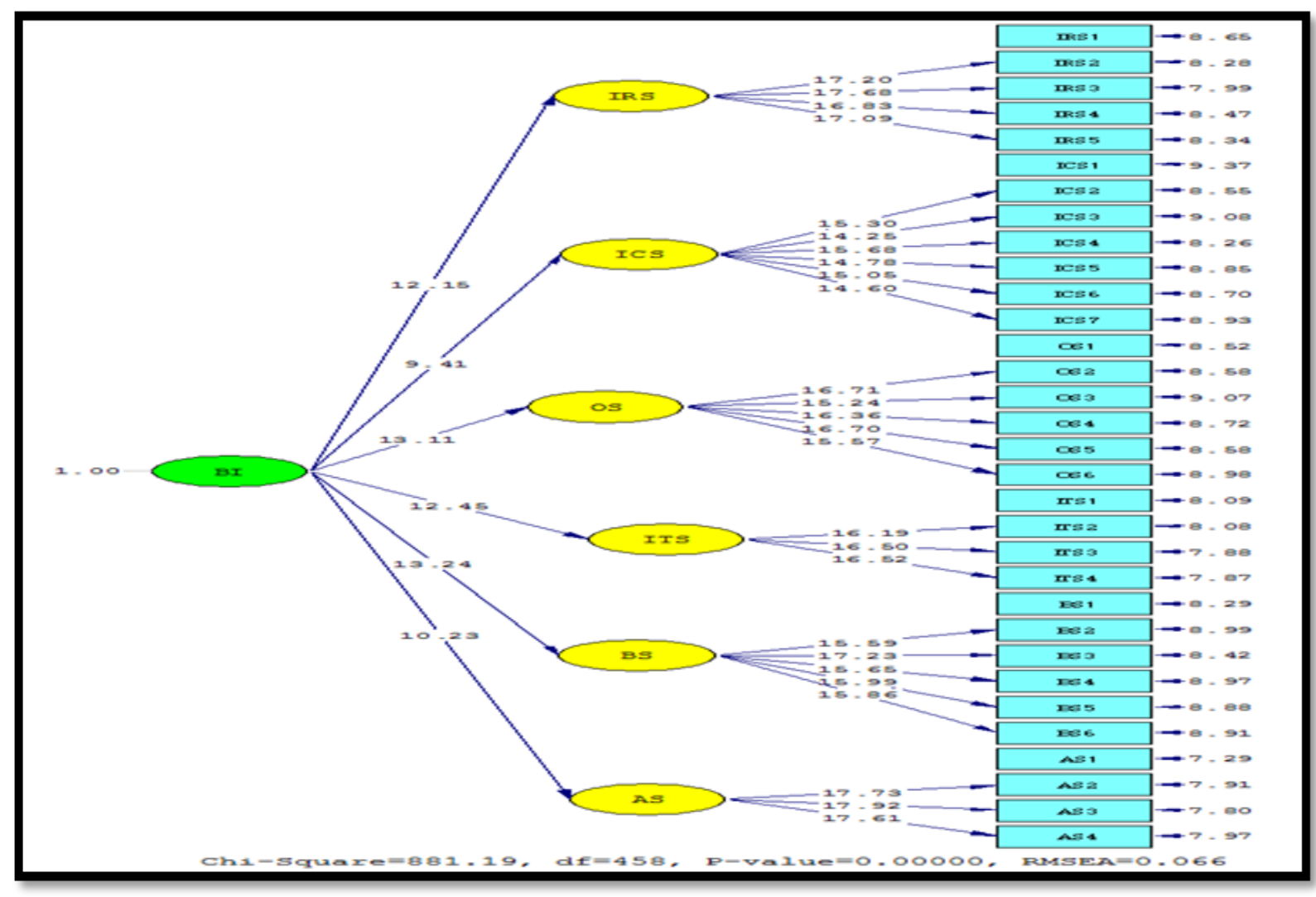

Indices of Model fitness indicate that the model is in a good condition considering appropriateness and fitness indices; because the ratio of chi-square to its degrees of freedom equals to 1.9240 which is less than allowed amount of 3 and the mean squared error is equal to 0.066 , which is less than allowed amount of 0.1 . So it does not need to be modified. Pvalue is also less than 0.05 . Optimum value of goodness of the fit indicator and its modified must be more than $90 \%$ so that goodness of the fit indicator in this model is 0.95 and its modified amount is equal to 0.87 , which are appropriate.

\section{Conclusion and Recommendations}

The purpose of this study is analyzing Business Intelligence and presenting a comprehensive model for Nir Pars Company of Tehran. Operational aspects of "Business Intelligence" are comprised of 32 items and six factors of "Organizational skills, Business skills, IT skills, Intellectual relationship skills, Analytical skills and Intelligence Competencies Skill". Based on the conducted literature review and identification of its variables, six factors had the most important roles in "Business Intelligence". According to the analysis of results of SPSS and LISREL; the priority of the variables are "Organizational skills" and "business skills", "IT skills", "Intellectual relationship skills", "Analytical skills" and "Intelligence Competencies Skill" respectively.

As shown in Figure 3, all significance numbers related to main aspects of the model are statistically significant; because their significance number is greater than 1.96. Consequently, the relevant hypothesis is approved. "Intellectual relationship skills" factor with the significance number (12.15), "Intelligence Competencies Skill" factor with the significance number (9.41), "Organizational skills" factor with significance number (13.11), "and "IT 
skills" factor with the significance number (12.45), "Business skills" factor with the significance number (13.24) and "Analytical skills" factor with the significance number (10.23) have a positive and meaningful relation with "Business Intelligence". In this research, based on the results of standard estimation model, practical suggestions for improving the "Business Intelligence" are applicable to Nir Pars Company:

1. Since the most important indicator in "Intelligence Relationship Skill (IRS)" is "continuous communication with customers and receiving feedback in order to determine their needs and expectations", the establishment of a system to manage and control the delivery of products and customer service projects, reduction of waiting times for the customers to receive goods or services, the establishment of a system to receive feedback about company's products and service delivery provided by customers, creating a customer relationship management system, continuous measurement of customer satisfaction and tracking their requests, changing the organizational culture in order to believe in the sovereignty of consumer, etc. are recommended to promote "Intelligence Relationship Skill".

2. Since the most important indicator in "Intelligence Competency Skill" is "ability to analyze the performance of successful and unsuccessful competitors and organizations", identification of indicators related to the behavior and actions of competitors and then investigating these indicator to become familiar with future possible changes in the activities of competitors or market environment, awareness of the strategies of competitors in the market environment, identification of the strategies of successful and unsuccessful organizations and the creation of an appropriate strategy for your organization, necessary measures to improve the values curves of your organization according to the experience of successful organization to quickly respond to market changes are recommended to promote "Intelligence Competency Skill".

3. To promote "Organizational Skills", the most important dimension is "ability to make changes in the organizational structure suited for the changing environment". Therefore, accommodating the organization with the needs of the environment, changing the behavior of employees and aligning it with the new requirements, making on-time internal changes to adapt to events outside the organization, etc. are suggested.

4. To promote "Information Technology Skill", it is possible to use updated information and communication technologies to enhance and improve the effectiveness of organizations' processes. Therefore, forecasting and planning necessary trainings in information technology and security and staff's specialized skills enhancement, investigation and development of necessary information and computer systems, promoting technical knowledge of managers and employees for optimal utilization of information technology are suggested.

5. Creating alignment at different levels of organizational strategies leads to promotion in "Business Skills". Therefore, understanding levels of business strategy planning in company and style used in the formulation of strategy and monitoring its implementation, creating methods for associating businesses with organization's strategy, staff awareness from strategic objectives of each level in order to perform tasks to achieve these objectives, etc. are recommended.

6. Developing innovative technologies (attempting to replace outdated technology) and management of organizational technology portfolios improves "Analytical Skills". Therefore, holding training sessions for staff and management briefing room while using Internet to access updated information in training sessions are recommended. 


\section{Acknowledgement}

The authors are indebted of kind assistance of managers and employees of Nir Pars Company, respected university professors, and senior executives and managers. We would like to acknowledge all those who share their knowledge and guide us through the research.

\section{Corresponding Author}

\section{Davod ghiyasvand}

Corresponding Author, M.S. Candidate of Master Business Administration (MBA)

Isfahan Science and Research branch, Islamic Azad University, Isfahan, Iran

Email: d.ghiyasvand@gmail.com

Address: Science and Research Branch of Islamic Azad University, Shahroz Alley, Before the Crossroads Abshar, Abshar First Street, Khajoo Bridge, Isfahan, Iran.

Tel: +98- 912-2684809 - +98- 311-6624961

\section{Hadi Teimouri}

Assistant Professor, Management Department, University of Isfahan, Isfahan, Iran

Email: hadi_teimouri@yahoo.com

Address: College of Economy and Management, University of Isfahan, University Avenue,

Azadi Square, Isfahan, Iran.

P.O.Box: 8174673441

Tel: +98- 913-1690601- +98-311-7935205

\section{References}

1. Adelman S, Moss L, Barbusinski L. 2002. I found several definions of BI. Data Mining Review, available at: www.dmreview.com.[ Accessed: 4 June 2013].

2. Ahmad poor, Taheri N. 2007(1386). Five future business maker skills. . Available from: http://kar11.persianblog.ir/post/4 , [Accessed 7 June 2013].

3. Bahrami M, Arabzad M, Ghorbani M. 2012. Innovation in market management by utilizing business intelligence: introducing proposed framework. Procedia - Social and Behavioral Sciences, 41: 160-167.

4. Brace N, Richard Kemp R, Snelgar R.2012. SPSS for Psychologists: Fifth Edition, Routledge; 5 editions, 488p.

5. Cochran, W. G. 1977. Sampling Techniques, Third Edition, New York: John Wiley \& Sons, Inc.

6. Elbashir M, Collier PA, Davern MJ. 2008. Measuring the effects of business intelligence system: the relationship between business process and organizational performance, International Journal of Accounting Information Systems, V. 9, 3: $135-153$.

7. Green a. 2007. Knowledge valuation business information a neutral path to business intelligence: knowing what to capture, the journal of Information and Knowledge Management Systems, V.37, 1:18-23.

8. Howston C. 2008. Successful business intelligence: secret to making BI a killer app. 1th edition, The McGraw-Hill companies, $244 \mathrm{p}$.

9. Malhotra Y. 2000. From information management to knowledge management: beyond the 'hi-techn hidebound' systems. Knowledge Management for the Information Professional. K.a. K. Srikantaiah, M.E.D. Medford, New Jersey, Information Today, Inc: 37 - 61. 
10. Olszak CM, Ziemba E. 2007. Approach to building and implementing business intelligence system. In: Interdisciplinary Journal of Information Knowledge and Management, V.2, 135-148.

11. Schumacker R. E, Lomax R. G. A .2010. Beginner's Guide to Structural Equation Modeling, Routledge; 3th edition, $536 \mathrm{p}$.

12. Zengyou He, Xiaofei Xu, Zhexue Huang J, Shengchun D. 2004. Mining class outliers: concepts, algorithms and applications in CRM. Expert Syst. Appl. V.27, 4: 681-697. 